\title{
Erratum to: HRQoL questionnaire evaluation in lactose intolerant patients with adverse reactions to foods
}

\section{Erminia Ridolo - Ilaria Baiardini - Tiziana Meschi •}

Silvia Peveri • Antonio Nouvenne • Pierpaolo Dall'Aglio •

Loris Borghi

Published online: 24 February 2012

(c) SIMI 2012

Erratum to: Intern Emerg Med

DOI 10.1007/s11739-011-0630-7

Unfortunately, first and last name of each author has been swapped in the original version of the article.

The correct author group is listed below:

Erminia Ridolo · Ilaria Baiardini . Tiziana Meschi . Silvia Peveri - Antonio Nouvenne - Pierpaolo Dall'Aglio · Loris Borghi

The online version of the original article can be found under doi:10.1007/s11739-011-0630-7.

E. Ridolo $(\bowtie) \cdot$ T. Meschi · A. Nouvenne $\cdot$ L. Borghi Clinical Sciences, University of Parma, Parma, Italy

e-mail: erminia.ridolo@unipr.it

I. Baiardini

Allergy and Respiratory Disease, Department of Internal

Medicine, University of Genoa, Genoa, Italy

S. Peveri · P. Dall'Aglio

Clinical Medicine, Nephrology and Health Science,

University of Parma, via Gramsci 14, 43100 Parma, Italy 